Revista de Ciencias Sociales - Número 69 (2016) - Páginas 189-221

El término de los plazos administrativos: análisis crítico de la...

\title{
EL TÉRMINO DE LOS PLAZOS ADMINISTRATIVOS: ANÁLISIS CRÍTICO DE LA JURISPRUDENCIA DE LA CONTRALORÍA GENERAL DE LA REPÚBLICA
}

\author{
THE TERMINATION OF THE ADMINISTRATIVE \\ DEADLINES: CRITICAL ANALYSIS OF THE \\ JURISPRUDENCE OF THE GENERAL \\ COMPTROLLER OF THE REPUBLIC
}

\author{
FLAVIO QUEZADA RODRÍGUEZ* \\ Universidad Alberto Hurtado \\ flavioqr@gmail.com
}

\section{Resumen}

La Contraloría General de la República sostiene que los plazos administrativos fenecen o terminan al momento de finalizar el horario de atención al público del último día del respectivo plazo. Dicho criterio es criticado, por cuanto se afirma que no existe razón jurídica alguna para excluir la aplicación de las reglas del Código Civil, que establecen su término en la media noche del mismo día. Por otro lado, dado que respetar la integridad del

\footnotetext{
* Abogado. Licenciado en Ciencias Jurídicas y Sociales, Universidad de Chile. Magíster en Derecho, mención Derecho Público, Universidad de Chile. Profesor de Derecho Administrativo en la Facultad de Derecho de la Universidad Alberto Hurtado, Santiago, Chile. Artículo recibido el 3 de noviembre de 2016 y aceptado el 15 de diciembre de 2016.
}

Revista de Ciencias Sociales - Número 69 (2016) - Universidad de Valparáíso - ISSN 0716-7725-Valparaíso, Chile 
plazo podría dar lugar a inconvenientes de índole práctico, se ofrece una propuesta de interpretación legal que podría sortearlos, fundada, también, en jurisprudencia de dicho organismo de control.

\section{Palabras claves}

Término de plazos, plazos administrativos, procedimiento administrativo.

\section{Abstract}

The General Comptroller of Chile has said that the administrative deadlines cease on the last day of the expiring date, when the customer service closes. This criteria has been criticized because some authors have stated that there is no legal argument that supports excluding the application of the rules of the Civil Code that fix midnight of the same day as the expiring term. On the other hand, due to the fact that fulfillment of this legal term could become unsuitable in practice, this paper proposes a legal interpretation that may tackle such difficulties, based on the already established practice of the referred authority.

\section{Keywords}

Deadlines, administrative deadlines, administrative proceeding.

\section{Introducción}

La jurisprudencia de la Contraloría General de la República históricamente ha sostenido que para la determinación del término de los plazos administrativos, esto es, el momento preciso en el cual aquellos fenecen, las disposiciones supletorias contenidas en el Código Civil deben ser aplicadas en forma armónica con los preceptos del Derecho Administrativo relativos a la marcha y funcionamiento de las oficinas públicas, de manera que dicho momento no puede ser considerado como la medianoche del último día del respectivo plazo, sino una vez expirado el horario legal de atención al público.

Dicho criterio se remonta a la década de los 50', y ha sido reafirmado muy recientemente en diversos dictámenes, a pesar de las modificaciones legales posteriores que permitirían arribar a otras conclusiones interpretativas.

Facultad de Derecho y Ciencias Sociales - Universidad de Valparaíso - Chile 
Una de los principales cambios normativos acaecidos con posterioridad del establecimiento de dicho criterio jurisprudencial es la introducción del principio-derecho subjetivo a la participación ciudadana en la gestión pública, el cual impone criterios hermenéuticos insoslayables para este asunto.

Asimismo, con posterioridad ha entrado en vigencia la ley $\mathrm{N}^{\circ} 19.880$ que establece Bases de los Procedimientos Administrativos que Rigen los Actos de los Órganos de la Administración del Estado (en adelante, LBPA). Esta ley resulta capital, respecto al término de los plazos administrativos, a lo menos, por dos razones: (i) introduce un marco legal nuevo respecto a los plazos en el procedimiento administrativo, no obstante no pronunciarse respecto a su término; y (ii) establece la equivalencia jurídica, en el procedimiento administrativo, entre el soporte material y el electrónico.

La relevancia de lo anterior está dada porque el silencio del legislador respecto al tema del término de estos plazos en la LBPA permite seguir sosteniendo la aplicación supletoria de los artículos 48, 49 y 50 del Código Civil, con lo cual debiera concluirse que aquellos fenecen a media noche del último día del respectivo plazo de días, meses o años; mientras que la equivalencia jurídica del soporte permite respetar la integridad de los plazos sin conllevar consecuencias indeseadas para la buena marcha de los servicios públicos: mediante una simple resolución administrativa interna que disponga que las presentaciones de interesados se efectuarán materialmente hasta el término del horario de atención al público y, posteriormente, mediante correo electrónico o un medio equivalente.

La solución antes enunciada no resulta inusitada o descabellada, toda vez que ha sido reconocida expresamente por la jurisprudencia del Ente Contralor.

En síntesis, el criterio de la jurisprudencia administrativa ha quedado desfasado: resulta jurídicamente improcedente y, en la práctica, innecesario. Es jurídicamente improcedente, toda vez que existen textos positivos expresos que permiten concluir que los plazos administrativos de días, meses y años fenecen a media noche de su último día; y resulta innecesario, por cuanto una simple resolución interna de "buen servicio" permitiría respetar dichos plazos en su integridad, sin conllevar gasto

Revista de Ciencias Sociales - Número 69 (2016) - Universidad de Valparáíso - ISSN 0716-7725-Valparáiso, Chile 
público excesivo o innecesario, o trabajo adicional de los servidores públicos.

Para desarrollar lo previamente expuesto, se seguirá el siguiente esquema:

1. Síntesis del criterio sostenido por la Contraloría General de la República respecto al término de los plazos administrativos.

2. Exposición del marco constitucional y legal de la participación ciudadana en el Derecho Administrativo chileno, haciendo especial referencia a su función en el procedimiento administrativo. Así, podrán establecerse criterios hermenéuticos imprescindibles para la correcta resolución de este asunto.

3. Desarrollo el marco legal referente al término de los plazos administrativos, asentando la distinción entre "plazo" y "término". En este punto, además de ofrecer la interpretación correcta, se criticarán los fundamentos de lo sostenido históricamente por la jurisprudencia administrativa.

4. Finalmente, se expondrá, con la colaboración de un preclaro dictamen de la Contraloría General de la República, una posibilidad interpretativa que permitiría respetar la integridad de los plazos administrativos sin conllevar problemas prácticos de relevancia.

\section{La jurisprudencia administrativa: un histórico criterio}

Como se señaló previamente, la Contraloría General de la República sostiene que no deben aplicarse las normas del Código Civil referentes al término de plazos de días, meses y años a los plazos administrativos del mismo tipo. Su postura puede ser sintetizada en el siguiente extracto:

“...acorde con la jurisprudencia de este origen contenida, entre otros, en los dictámenes 43.317, de 1958; 62.892, de 1978; y 8.678, de 1983; los artículos 48 y 49 del Código Civil deben ser aplicados en forma armónica con los preceptos de derecho administrativo relativos a la marcha y funcionamiento de las diversas oficinas de la Administración, lo que implica que los plazos deben

\footnotetext{
Facultad de Derecho y Ciencias Sociales - Universidad de Valparaíso - Chile
} 
entenderse transcurridos una vez que haya expirado el horario legal de atención al público, y que extender los plazos en cuestión hasta el día siguiente a su vencimiento implica prorrogar sin facultad alguna un término que se encuentra fenecido" (Dictamen $\mathrm{N}^{\circ}$ 5.608, de 2017).

En otras palabras, la "marcha y funcionamiento" de la Administración del Estado obstaría a la aplicación de las disposiciones del Código Civil, según las cuales los plazos fenecen a media noche de su último día. De este modo, su término estaría dado por el "horario legal de atención al público" del último día. Así, curiosamente, sin razones de texto positivo se han dejado de aplicar disposiciones legales expresas, acortando los plazos administrativos de una forma que convierte, por ejemplo, al plazo general para impugnar administrativamente de cinco días a cuatro y un número variable de horas, según la decisión discrecional de la respectiva jefatura superior del servicio.

Asimismo, el mismo criterio también sostiene algo jurídicamente preciso: no podrían las jefaturas superiores disponer la recepción de presentaciones el día siguiente del término del plazo, toda vez que aquello constituiría una prórroga sin la respectiva habilitación legal.

Corresponde preguntarse, entonces, si dado el derecho vigente, solo son posibles esas dos alternativas: (i) término de plazos administrativos al finalizar la hora de atención al público o (ii) prórroga hasta el día siguiente sin habilitación legal. Como se expondrá más adelante, sin descartar otras opciones, y desde la propia jurisprudencia de la Contraloría, es posible arribar a una solución diversa que permita respetar la integridad de los plazos administrativos de forma compatible con la "buena marcha" de los servicios públicos, conforme los principios de eficacia y eficiencia que rigen la función administrativa.

Por cierto, lo anterior no resulta una discusión dogmática baladí, por cuanto la mantención del criterio jurisprudencial afecta ilegítimamente derechos sustantivos y adjetivos de los interesados en un procedimiento administrativo y, asimismo, obsta a maximizar la probabilidad de corrección de la decisión pública, con lo cual el interés público también está en juego.

Revista de Ciencias Sociales - Número 69 (2016) - Universidad de Valparáíso - ISSN 0716-7725-Valparaíso, Chile 


\section{La participación ciudadana en el Derecho Administrativo chileno}

La ley $\mathrm{N}^{\circ} 20.500$ sobre Asociaciones y Participación Ciudadana en la Gestión Pública introdujo diversas modificaciones al ordenamiento jurídico, entre ellas, estableció el principio de participación ciudadana en la gestión pública como un elemento basal o fundante del Derecho Administrativo chileno.

Lo anterior impone a una nueva lectura de las normas que regulan los procedimientos administrativos, asignándole un nuevo valor a la participación de los particulares en la materialización del interés público, es decir, a los derechos adjetivos o procedimentales de aquellos. Un corolario relevante para la dilucidación del régimen del término de los plazos administrativos es que constituirá, a su vez, un criterio hermenéutico que deberá ser considerado.

Para desarrollar este punto, resulta necesario explicar el valor epistémico de la participación ciudadana para la corrección de la decisión pública, y luego exponer cómo aquello ha sido acogido positivamente en las normas reguladoras de la función administrativa.

\section{a) El valor epistémico de la participación ciudadana en el procedimiento administrativo}

La participación ciudadana, como principio basal, haya su fundamento en aquello que construye todo el Derecho Administrativo: el interés público. En efecto, promover y facilitar que los interesados (utilizando la nomenclatura de la LBPA) presenten alegaciones, documentos, pruebas, contradigan, etc., no debiera sólo considerarse desde una óptica subjetiva o individualista, es decir, como expresiones de derechos subjetivos, sino que son, también, condiciones para una decisión pública más probablemente correcta. En otros términos, facilitar y promover la participación ciudadana en la gestión pública permite, como condición epistémica del procedimiento administrativo, que ella más se aproxime de forma más eficaz y eficiente a la corrección.

Para evidenciar este punto, piénsese en el extremo de una intervención pública exclusivamente unilateral, sin ningún tipo de interacción de los eventuales afectados, muy probablemente generaría

Facultad de Derecho y Ciencias Sociales - Universidad de Valparaíso - Chile 
cierto tipo de resistencia social que afectaría la eficacia y eficiencia de la decisión. Por ello, en nuestro medio, MORAGA ha sostenido que “...el mecanismo que mejor promueve o facilita que la decisión administrativa final sea legítima y legal"'.

Ello es así, por cuanto quienes se encuentran en la mejor posición para considerar aspectos relevantes de la decisión (los afectados por ella), incorporarán al proceso decisional perspectivas imprescindibles para la adopción de una decisión correcta y, por tanto, se permitirá así la racionalización de la actuación de la Administración ${ }^{2}$. Desde esta perspectiva, las personas cuyos intereses pudiesen estar comprometidos en la actuación pública aparecen no como "enemigos" del interés público, sino como colaboradores ${ }^{3}$.

Se debe precisar que no se trata de negociar el interés público con los particulares, ni que sus intereses sean ponderados con aquél por la Administración, a fin de construir un híbrido interés públicointereses privados (de dudosa legitimidad constitucional); sino que ella, al considerar sus apreciaciones, aumenta la probabilidad de corrección de su decisión de concreción del interés público o bien común, al incorporar al proceso decisional los puntos de vista de quienes están en la mejor posición para hacerle considerar lo relevante. Por muy tecnificadas y profesionalizadas que sean las Administraciones actuales,

1. MORAGA, Claudio: Tratado de Derecho Administrativo. Tomo VII. La actividad formal de la Administración del Estado. AbeledoPerrot-Legalpublishing, Santiago, 2010. Pág. 8.

2. Así lo explica SCHMIDT-ASSMANN: “...la institución del procedimiento administrativo resulta útil para estructurar y garantizar la racionalidad de la acción estatal. En ese sentido, el procedimiento no es sino un diseño inteligente de reglas cuyo propósito reside en asegurar que las decisiones se adopten de forma transparente, que el producto final sea de calidad, y resulte efectiva la capacidad de aprendizaje y de acumulación de experiencia”. SCHMIDT-ASSMANN, Eberhard. "Pluralidad de estructuras y funciones de los procedimientos administrativos en el derecho alemán, europeo e internacional”. En: Barnés, Javier (Editor): La transformación del procedimiento administrativo. Global Law Press Editorial Derecho Global, Sevilla, 2008. Pág. 77.

3. MORAGA, Claudio. Tratado de Derecho Administrativo. Op. Cit. Pp. 8-11. 
los hechos siempre acontecen fuera de ella y son vividos por los particulares, por lo que no es posible prescindir de ellos.

De este modo, considerando el valor epistémico de la participación ciudadana, el legislador chileno ha decidido erguirla en un principio fundamental de todo el Derecho Administrativo nacional, lo cual, conforme los desarrollos que le ha dado la jurisprudencia constitucional, impone a los operadores jurídicos ciertos criterios hermenéuticos ineludibles para la determinación del término de los plazos administrativos. En efecto, aquello es así, toda vez que dichos eventos fijan oportunidades para la participación ciudadana, de manera que interpretaciones restrictivas podrían obstaculizarla.

\section{b) Consideraciones dogmáticas}

Una de las modificaciones introducidas por la ley $\mathrm{N}^{\circ} 20.500$ fue la introducción de un nuevo principio básico para toda la Administración del Estado: la participación ciudadana en la gestión pública, constituyéndose en uno de aquellos principios que debe observar. Así lo dispone el inciso segundo del artículo $3^{\circ} \mathrm{LOCBGAE}^{4}$.

Con posterioridad, dicho cuerpo normativo cuenta con un título especial que desarrolla dicho principio. En sus disposiciones se reconoce un verdadero derecho subjetivo a la participación ciudadana, el cual está establecido en el artículo 69 de la LOCBGAE en los siguientes términos:

"Artículo 69.- El Estado reconoce a las personas el derecho de participar en sus políticas, planes, programas y acciones.

4. Dispone dicha norma: "La Administración del Estado deberá observar los principios de responsabilidad, eficiencia, eficacia, coordinación, impulsión de oficio del procedimiento, impugnabilidad de los actos administrativos, control, probidad, transparencia y publicidad administrativas y participación ciudadana en la gestión pública, garantizará la debida autonomía de los grupos intermedios de la sociedad para cumplir sus propios fines específicos, respetando el derecho de las personas para realizar cualquier actividad económica en conformidad con la Constitución Política y las leyes".

Facultad de Derecho y Ciencias Sociales - Universidad de Valparaíso - Chile 
Es contraria a las normas establecidas en este Título toda conducta destinada a excluir o discriminar, sin razón justificada, el ejercicio del derecho de participación ciudadana señalado en el inciso anterior".

Por su parte, el Tribunal Constitucional ha reconocido el rango constitucional de dicho principio y del respectivo derecho subjetivo, anclándolo en el inciso final del artículo $1^{\circ}$ de la Constitución:

“...las modalidades formales y específicas de participación que tendrán las personas y organizaciones que establezcan los órganos de la Administración del Estado, deben tener por objeto facilitar y promover, no entrabar, el derecho establecido en el artículo $1^{\circ}$, inciso final, de la Constitución Política, en relación con el artículo $5^{\circ}$ de la misma, en orden a que las personas puedan participar con igualdad de oportunidades en la vida nacional" (STC Rol $\mathrm{N}^{\circ} 1868$, c. 16$)^{5}$.

Entonces, como se sigue de lo desarrollado previamente, participar en la gestión pública constituye un derecho subjetivo de los ciudadanos, legal y constitucionalmente reconocido. El sujeto obligado, en este caso, es la Administración del Estado, y sobre ella recae un deber de "facilitar y promover" (faz positiva) y una prohibición de "no entrabar" (faz negativa), respecto a dicho derecho.

Dicha faz positiva tiene una importante consecuencia hermenéutica respecto al marco legal de la actuación administrativa: obliga a interpretar las normas que regulan la participación ciudadana con un criterio finalista, que la facilite y promueva. Así, de un abanico de

5. En este mismo sentido, dicho tribunal ha sostenido: “...la Carta Democrática Interamericana, en su artículo $6^{\circ}$, afirma que "[1]a participación de la ciudadanía en las decisiones relativas a su propio desarrollo [...es] una condición necesaria para el pleno y efectivo ejercicio de la democracia”. Esto último, en concordancia por lo demás con lo que establece el inciso final del artículo $1^{\circ}$ de la Constitución Política de la República, en cuanto impone al Estado el deber de asegurar el derecho de las personas a participar con igualdad de oportunidades en la vida nacional” (STC Rol N 1732, c. 14. En el mismo sentido, STC Rol N 1812, c. 48).

Revista de Ciencias Sociales - Número 69 (2016) - Universidad de Valparáíso - ISSN 0716-7725-Valparaíso, Chile 
interpretaciones plausibles, ha de optarse siempre por aquella que más y mejor permita la expresión ciudadana en el ejercicio de las potestades pública.

Aplicando lo anterior al término de los plazos administrativos, es posible sostener que se ajusta de mejor manera a dicho principio el respeto a la integridad de dichos plazos. La directriz hermenéutica guía en dicha dirección al intérprete.

\section{Los plazos en el procedimiento administrativo}

La participación ciudadana, por cierto, deberá realizarse en un contexto procedimental, el cual, para poder desenvolverse adecuadamente ha de contar con etapas, plazos, oportunidades, etc. Es decir, ha de contar con todo un conjunto de ritualidades legales que materialicen aquella exigencia del artículo $7^{\circ}$ de la Constitución: “...en la forma que prescriba la ley".

Un elemento fundamental para el desenvolvimiento del procedimiento son los plazos, que, como se verá, en el Derecho Administrativo cuenta con un marco legal propio que resulta necesario desarrollar para los fines de este trabajo. Para ello, se expondrán su concepto y elementos, lo que permitirá detenerse en uno de ellos: su término y, así, aquilatar sistémicamente su regulación vigente.

\section{a) Concepto y elementos del plazo}

Se entiende por plazo “...el lapso, el período o el intervalo de tiempo que corre entre dos momentos" ${ }^{\prime}$, mientras que, por su parte, el término constituye "el límite que culmina ese plazo"7. Es decir, cada plazo tiene un momento de inicio y otro de término, entre los cuales transcurre un determinado o determinable período de tiempo.

6. PINILLA, Álvaro: "Breves comentarios a las reglas vigentes para el cómputo de plazos o términos de origen legal". En: Revista de Derecho Privado, $\mathrm{N}^{\circ} 24$, 2013. Pág. 285.

7. Ídem.

Facultad de Derecho y Ciencias Sociales - Universidad de Valparaíso - Chile 
En nuestro medio, Luis CORDERO ha señalado que se entiende por plazo “....aquel espacio de tiempo que fija el ordenamiento jurídico para que un órgano de la Administración ejerza sus potestades o para que un particular que se vincula con dichos órganos ejerza sus derechos o cumpla sus obligaciones.

Mientras en el derecho privado prevalecen los plazos convencionales, en el derecho público los plazos los establece la ley o el reglamento"

En específico, el problema que acá se analiza dice relación con la correcta determinación de la regulación de los plazos de días, meses y años para o ante la Administración del Estado, es decir, aquellos que la ley le impone para actuar o a las ritualidades que debe seguir, como los prescritos para realizar actuaciones por los particulares ante sus organismos. Esta materia, con posterioridad a las modificaciones introducidas por la LBPA, ha dado lugar una nueva categoría jurídica: los plazos administrativos ${ }^{9}$, la cual surgiría por las regulaciones especiales relativas a su cómputo.

Previo a la LBPA resultaba indiscutible la aplicación de la regulación del cómputo de plazos establecido en el Código Civil ${ }^{10}$. Con posterioridad, sin embargo, esta materia cuenta con nuevas disposiciones las que, sin embargo, nada dicen respecto al término de estos plazos, lo cual conlleva a preguntarse cuál es la norma regula esta materia.

El punto es de suma relevancia, toda vez que su correcta interpretación permitirá la efectividad material de derechos sustantivos ante la Administración y la participación ciudadana, como la creación de las

8. CORDERO, Luis: Lecciones de Derecho Administrativo. Thomson Reuters, Santiago, 2015. Pág. 390-391.

9. VERGARA, Alejandro: "Cómputo e interrupción de plazos en el procedimiento administrativo. Micrología del principio de certeza jurídica”. En: Soto, Eduardo (Coord.): Administración y Derecho. Homenaje a los 125 años de la Facultad de Derecho de la Pontificia Universidad Católica de Chile. Santiago, LegalPublishing, 2014. Pág. 303.

10. Al respecto, ver dictámenes No 1.610, de 1976; 9.945, de 1990; 28.647, de 1999 y 9.740 , de 2003 .

Revista de Ciencias Sociales - Número 69 (2016) - Universidad de Valparáíso - ISSN 0716-7725-Valparaíso, Chile 
condiciones de posibilidad de corrección de la decisión pública. Tan así, que cierta doctrina ha llegado a sostener que existiría "un nuevo derecho público subjetivo de los administrados": "el derecho al plazo administrativo" ${ }^{11}$.

\section{b) El término de los plazos legales de días, meses y años}

En nuestro ordenamiento jurídico, el marco general de los plazos administrativos está contenido en diversas disposiciones legales: LOCBGAE, LBPA y el Código Civil.

En primer lugar, el inciso segundo del artículo 8 LOCBGAE impone un principio rector en la interpretación uniformadora de los procedimientos administrativos, al señalar que estos “deberán” ser ágiles y expeditos, precisando que solo la ley y reglamentos podrán establecer formalidades. Por cierto, aquellas formalidades han de permitir la agilidad y expedición de los procedimientos, no obstar a aquello. Este mandato cuenta con concretas expresiones en los principios de la LBPA (celeridad, economía procedimental, no formalización, a lo menos). Posteriormente, el mismo cuerpo legal (LBPA) regula diversos aspectos de los plazos administrativos en sus artículos 23 al 27. Para dilucidar el problema planteado, resulta necesario detenerse en los artículos 23 y 25.

Este marco legal, configurado por la LOCBGAE y la LBPA, es particularmente relevante, atendido su carácter genérico y supletorio que le otorga el ámbito de aplicación de ambas leyes.

\section{i) Los artículos 23 y 25 de la LBPA}

El artículo 23 de la $\mathrm{LBPA}^{12}$ debe leerse con atención: distingue, utilizando la disyunción “y”, entre términos y plazos legales, tal como

\footnotetext{
11. Ídem.

12. "Artículo 23. Obligación de cumplimiento de los plazos. Los términos y plazos establecidos en ésta u otras leyes obligan a las autoridades y personal al servicio de la Administración en la tramitación de los asuntos, así como los interesados en los mismos".
}

Facultad de Derecho y Ciencias Sociales - Universidad de Valparaíso - Chile 
lo hace la doctrina, e impone que ambos sean cumplidos tanto por las autoridades, funcionarios, como a los interesados; de manera que ninguno de ellos podrá desconocer términos si la ley los establece.

Lo anterior, por cierto, no obsta a la renuncia tácita a la extensión total o parcial de un plazo que acontece cada vez que la Administración dicta un acto antes del respectivo vencimiento o cuando un particular realiza su presentación con anticipación al término legal. Sin embargo, resulta discutible si podría renunciarse de forma anticipada a los plazos legales respecto de la Administración, por cuanto ello pugnaría con los principios de eficacia y eficiencia, toda vez que siempre han de modelarse con la concreta situación fáctica de decisión.

Por su parte, el artículo 25 de la $\mathrm{LBPA}^{13}$ establece reglas referentes al cómputo de plazos de días ante la Administración, señalando que solo se contabilizarán aquellos días "hábiles", excluyendo de dicha categoría los "sábados, domingos y festivos".

Con posterioridad, en su inciso segundo, reconoce los viejos adagios latinos, según el cual "dies a quo non computatur in termino", es decir, el momento a partir del cual principia a contarse un plazo no se computa dentro del mismo; y "dies ad quem computatur in termino", esto es, el momento en que finaliza el plazo se incluye dentro del mismo, haciéndose parte de él.

Finalmente, establece que si un plazo culmina un día inhábil, éste se prorrogará hasta el primer día hábil siguiente.

Como puede verse, de las dos disposiciones legales antes analizadas es posible extraer como conclusiones (i) la obligatoriedad para la Administración de los plazos y sus respectivos términos legales, la cual

13. "Artículo 25. Cómputo de los plazos del procedimiento administrativo. Los plazos de días establecidos en esta ley son de días hábiles, entendiéndose que son inhábiles los días sábados, los domingos y los festivos.

Los plazos se computarán desde el día siguiente a aquél en que se notifique o publique el acto de que se trate o se produzca su estimación o su desestimación en virtud del silencio administrativo. Si en el mes de vencimiento no hubiere equivalente al día del mes en que comienza el cómputo, se entenderá que el plazo expira el último día de aquel mes.

Cuando el último día del plazo sea inhábil, éste se entenderá prorrogado al primer día hábil siguiente”.

Revista de Ciencias Sociales - Número 69 (2016) - Universidad de Valparáíso - ISSN 0716-7725-Valparaíso, Chile 
no podrá desconocerlos so riesgo de irregularidad en su actuación; y (ii) una regla especial respecto al cómputo de días hábiles en los plazos administrativos, pero, como se sigue de su simple lectura, nada señala respecto al término de aquellos, es decir, no se regula en qué momento fenecen.

En consecuencia, corresponderá plantearse la interrogante respecto a qué normas regulan esta materia, y no puede sino responderse que serán aquellas del Código Civil, por cuanto, en nuestro ordenamiento jurídico, no existe norma legal expresa que haga excepción para los procedimientos administrativos (ni para las actuaciones de la Administración, ni ante ella), de sus disposiciones referentes al término de los plazos, las cuales, como se verá, establecen reglas generales y supletorias para todos los plazos dispuestos en el ordenamiento jurídico.

\section{ii) Artículos 48, 49 y 50 del Código Civil}

El Código Civil establece las normas generales y supletorias respecto a la regulación del término de plazos, atendido su contenido expreso, de manera que sus disposiciones solo pueden ser excepcionadas si una ley especial así lo establece. Dichas disposiciones las encontraremos en los artículos 48, 49 y 50 del Código Civil ${ }^{14}$.

14. "Art. 48. Todos los plazos de días, meses o años de que se haga mención en las leyes o en los decretos del Presidente de la República, de los tribunales o juzgados, se entenderá que han de ser completos; y correrán además hasta la medianoche del último día del plazo.

El primero y último día de un plazo de meses o años deberán tener un mismo número en los respectivos meses.

El plazo de un mes podrá ser, por consiguiente, de 28, 29, 30 ó 31 días, y el plazo de un año de 365 ó 366 días, según los casos.

Si el mes en que ha de principiar un plazo de meses o años constare de más días que el mes en que ha de terminar el plazo, y si el plazo corriere desde alguno de los días en que el primero de dichos meses excede al segundo, el último día del plazo será el último día de este segundo mes.

Se aplicarán estas reglas a las prescripciones, a las calificaciones de edad, y en general a cualesquiera plazos o términos prescritos en las leyes o en los actos de las autoridades chilenas; salvo que en las mismas leyes o actos se disponga expresamente otra cosa".

Facultad de Derecho y Ciencias Sociales - Universidad de Valparaíso - Chile 
De dichas disposiciones ha de concluirse que los plazos administrativos de días, meses y años tienen su término en la medianoche del último día, como se sigue de su tenor literal. No existe norma que haga excepción, tácita o expresa, a lo ahí señalado.

Sin embargo, para evidenciar la corrección jurídica de esta interpretación, es necesario hacerse cargo de explicar por qué el criterio sostenido por la jurisprudencia administrativa debería ser desechado. Para ello, primero se plantearán las objeciones al criterio de la Contraloría General de la República; y, luego, se propondrá una solución que puede seguirse desde las posibilidades interpretativas de la LBPA.

\section{c) Objeciones al criterio de la jurisprudencia administrativa}

Como se sintetizó previamente, la jurisprudencia administrativa sostiene que los plazos administrativos fenecen su último día, en el momento de término del horario de atención al público de las reparticiones públicas, no pudiendo extenderse hasta el día siguiente. Para poder objetar esta tesis, resulta necesario exponer sus fundamentos jurídicos, los cuales son claramente desarrollados en el siguiente pronunciamiento:

“...cabe recordar que la ley $\mathrm{N}^{\circ} 11.764$, en su artículo 42 establece que "Las oficinas fiscales, semifiscales y de administración autónoma tendrán un horario uniforme de atención al público". Por su parte, el decreto $\mathrm{N}^{\circ} 1.897$, de 1965, del Ministerio del Interior, que Reglamenta la Implantación de Jornada única o

"Art. 49. Cuando se dice que un acto debe ejecutarse en o dentro de cierto plazo, se entenderá que vale si se ejecuta antes de la medianoche en que termina el último día del plazo; y cuando se exige que haya transcurrido un espacio de tiempo para que nazcan o expiren ciertos derechos, se entenderá que estos derechos no nacen o expiran sino después de la medianoche en que termine el último día de dicho espacio de tiempo".

"Art. 50. En los plazos que se señalaren en las leyes, o en los decretos del Presidente de la República, o de los tribunales o juzgados, se comprenderán aun los días feriados; a menos que el plazo señalado sea de días útiles, expresándose así, pues en tal caso no se contarán los feriados”.

Revista de Ciencias Sociales - Número 69 (2016) - Universidad de Valparaíso - ISSN 0716-7725-Valparaíso, Chile 
Continua de Trabajo, establece en su $\mathrm{N}^{\circ} 3^{\circ}$, letra d), inciso segundo, que los servicios públicos, en general, iniciarán sus labores entre las 8.30 y 9.00 horas, añadiendo su inciso séptimo que destinarán por lo menos 2 horas diarias para la atención del público en las oficinas que cada uno de ellos determine.

A su vez, el artículo 65 del Estatuto Administrativo contenido en la ley $\mathrm{N}^{\circ} 18.834$, dispone que la jornada ordinaria de trabajo de los funcionarios será de cuarenta y cuatro horas semanales distribuidas de lunes a viernes, no pudiendo exceder de nueve horas diarias. Ello, por cierto, sin perjuicio de la ejecución de trabajos extraordinarios cuando hayan de cumplirse tareas impostergables, según lo permite de manera excepcional el artículo 66 de dicho cuerpo legal. Lo anterior resulta plenamente armónico con lo dispuesto en el artículo 25, inciso primero, de la ley $\mathrm{N}^{\circ}$ 19.880, que Establece Bases de los Procedimientos Administrativos que Rigen los Actos de los órganos de la Administración del Estado, en cuya virtud los plazos de días establecidos en esta ley son de días hábiles, entendiéndose que son inhábiles los días sábados, los domingos y los festivos.

Como se puede apreciar, en el ámbito administrativo existen normas especiales -entre las cuales están las citadas a vía de ejemplo en los párrafos que anteceden-, que regulan de manera diversa a como lo hace el Derecho Común, la forma en que se computan los plazos y su vencimiento, así como también el horario de funcionamiento de los servicios públicos.

En este sentido, el criterio seguido sobre la materia por la jurisprudencia de este órgano Fiscalizador, contenida en los dictámenes $\mathrm{N}^{\circ} 43.317$, de 1958; 8.678, de 1983 y 49.126, de 2008, entre otros, ha sostenido que las normas sobre plazos de días, meses o años contempladas en los artículos 48, 49 y 50 del Código Civil deben ser aplicadas en forma armónica con los preceptos de derecho administrativo relativos a la marcha y funcionamiento de las diversas oficinas de la Administración Pública, a lo cual debe agregarse que si bien de acuerdo con el Derecho Común los plazos para ejercer acciones administrativas como las mencionadas por los recurrentes, deben entenderse transcurridos la

Facultad de Derecho y Ciencias Sociales - Universidad de Valparaíso - Chile 
medianoche del día en que vencen, ello no obsta a que esta Entidad de Control, así como los demás organismos administrativos, deban cumplir las normas que regulan tanto la jornada de los funcionarios como el horario legal de atención al público, por lo que las presentaciones deben ingresarse en las respectivas oficinas de partes institucionales dentro de este horario". (Dictamen N ${ }^{\circ}$ 51.137, de 2011).

Como puede verse, el fundamento de la tesis del Ente Contralor es la existencia de “...normas especiales [...] que regulan de manera diversa a como lo hace el Derecho Común, la forma en que se computan los plazos y su vencimiento, así como también el horario de funcionamiento de los servicios públicos". Dichas normas “especiales" serían, a su juicio, aquellas referentes al (i) horario de atención al público de las reparticiones públicas (ley $\mathrm{N}^{\circ} 11.764$ ); y (ii) la jornada de trabajo de los funcionarios públicos (Estatuto Administrativo).

Sin embargo, como se expondrá, estos argumentos no pueden ser aceptados, por cuanto desde una atenta lectura de las disposiciones referidas, no se sigue este criterio jurisprudencial. Para explicar esto, se seguirá el siguiente plan:

i) El criterio sostenido por la jurisprudencia administrativa no facilita, sino que entraba ilegítimamente la participación ciudadana en los procedimientos administrativos.

ii) Dado el carácter general y supletorio de las disposiciones del Código Civil en esta materia, no pueden ser excepcionadas mediante normas administrativas internas, como aquellas que establecen el horario de atención del público, decisión discrecional de la jefatura superior del respectivo servicio, deslegalizada por la ley $\mathrm{N}^{\circ} 11.764$.

iii) Las normas legales que establecen la jornada de los funcionarios públicos se refiere a una materia ajena a la regulación legal del término de plazos administrativos, por tanto, tampoco no pueden excepcionar las normas generales y supletorias al respecto.

(iv) La jurisprudencia de la Contraloría General de la República no es tan tajante al respecto, es más, ha reconocido que los 
plazos administrativos encuentran la regulación de su término en el Código Civil.

v) La jurisprudencia de la Corte Suprema sigue la misma interpretación que acá se propone, señalando que cuando la Administración no respeta un plazo en toda su extensión constituye una actuación irregular inaceptable y que el término de los plazos administrativos se regula según las disposiciones del Código Civil.

A continuación se desarrollarán cada uno de estos argumentos:

\section{El principio de participación ciudadana como criterio hermenéutico}

Como se explicó, el artículo 8 LOCBGAE impone que los procedimientos administrativos "deberán" ser ágiles y expeditos, precisando que solo la ley y reglamentos podrán establecer sus formalidades. Por cierto, aquellas formalidades han de permitir la agilidad y expedición de los procedimientos, no obstar a aquello.

En este mismo sentido, Jorge BERMÚDEZ ha sostenido que: "El procedimiento administrativo puede resultar una carga para el ciudadano, incluso puede llegar a constituir una limitación en sus derechos fundamentales, producto del ejercicio discrecional que tiene la Administración Pública tanto en la configuración del procedimiento administrativo, como en el ejercicio de las medidas provisionales que le otorga la ley. En consecuencia, el procedimiento administrativo debe estar conformado de manera tal que sea adecuado a la finalidad que se persigue, sin que el ciudadano sufra el ejercicio de medidas desmesuradas o innecesarias durante la tramitación del mismo"15. Por su parte, Luis CORDERO, siguiendo la misma línea, ha planteado que: "Este principio es fruto de que el procedimiento debe ser aplicado en beneficio del ciudadano. Es decir, que las formalidades no pueden significar un impedimento para el ejercicio de derechos y la participación en el procedimiento administrativo" ${ }^{16}$.

15. BERMÚDEZ, Jorge: Derecho Administrativo General. $3^{\text {a }}$ edición actualizada. Legalpublishing, Santiago, 2014. Pág. 189.

16. CORDERO, Luis. Op. Cit. Pág. 370.

Facultad de Derecho y Ciencias Sociales - Universidad de Valparaíso - Chile 
Esa proscripción de medidas "desmesuradas o innecesarias" impediría que la Administración decida acortar los plazos administrativos por razones "de buen servicio", si bien podría disponer de otros medios para ellos, por ejemplo, señalando que recibirá presentaciones en soporte material hasta el término de su horario de atención al público y que, con posterioridad, las recibirá vía electrónica, conforme permite la LBPA. De esta forma, la decisión referente al establecimiento de dicho horario de atención no afectaría los derechos de los interesados en el procedimiento, en especial, la participación ciudadana. El mandato de "facilitar y promover" dicha participación, a la vez que "no entrabar", conllevan a preferir otras medidas, menos gravosas que lo que se sigue del criterio actual de la Contraloría General de la República. Así, no sólo se respetan los derechos adjetivos y sustantivos, sino, sobre todo, se resguardan las condiciones de posibilidad de corrección de la decisión pública a adoptar.

\section{El término legal de un plazo administrativo no puede ser modificado por resoluciones internas}

El horario de atención al público se encuentra regulado en disposiciones especiales de antigua data, las cuales, muy razonablemente, deslegalizan su fijación. En efecto, entregar el establecimiento de aquello a la determinación discrecional de la respectiva jefatura superior de cada servicio resulta adecuado, por cuanto la eficiencia de la gestión pública exigirá considerar las particularidades propias y el contexto de cada organismo. Sería irracional fijar (y por tanto rigidizar) una decisión de este tipo.

Sin embargo, derivar de dicha decisión la regulación de un elemento crucial de los plazos administrativos: su término, resulta difícilmente justificable, toda vez que el principio de juridicidad obsta a permitir que decisiones administrativas modifiquen decisiones legales, afectando derechos y sin habilitación expresa. Es más, ni siquiera se desprende de las reglas aplicables que, como se expondrá, no hacen referencia alguna a este tópico.

En efecto, la regulación referente al horario de atención al público de los servicios públicos se encuentra en la ley $\mathrm{N}^{\circ} 11.764$ y el decreto

Revista de Ciencias Sociales - Número 69 (2016) - Universidad de Valparaíso - ISSN 0716-7725-Valparaíso, Chile 
$\mathrm{N}^{\circ} 1.897$, de 1965, del Ministerio del Interior. El artículo 42 de aquella ley establece lo siguiente:

"Artículo 42. ${ }^{\circ}$ Las oficinas fiscales, semifiscales y de administración autónoma tendrán un horario uniforme de atención al público. Corresponderá al Presidente de la República fijar dicho horario y establecer sus excepciones en casos calificados”.

Por su parte, el decreto $\mathrm{N}^{\circ} 1.897$, de 1965 , del Ministerio del Interior, que reglamenta la implantación de jornada única o continua de trabajo, establece, en lo pertinente, lo siguiente:

" $3^{\circ}$ Las horas de iniciación de la jornada de trabajo para las actividades en que ella se aplicará, serán las siguientes:

[...]

d) Servicios Públicos: En general, iniciarán sus labores entre las 8,30 y 9,00 horas. Exceptúanse las Oficinas de la Dirección General del Trabajo y otras de especial atención de los trabajadores y de sus organizaciones, que, al efecto, señale la Subsecretaría del Trabajo, que comenzarán su jornada entre las 10,00 y 11,00 .

Sin perjuicio de lo dispuesto en el inciso anterior, la Caja de Accidentes del Trabajo iniciará sus labores entre las 8.30 y 9.00 horas.

La hora de iniciación de la jornada de trabajo será precisada por cada Secretaría de Estado para los Servicios de su dependencia o que se relacionen con ella, de acuerdo con las normas antes señaladas y deberá ser comunicada al Ministerio del Interior. Todos los funcionarios estarán obligados al cumplimiento del horario fijado para el respectivo Servicio, inclusive los Jefes y Empleados Superiores con la salvedad de otras obligaciones inherentes a los cargos de éstos. No obstante, los Jefes Superiores regularán el horario de los profesionales y los turnos de los funcionarios que se requieran para las necesidades del respectivo Servicio, en cuyo caso podrá fijarse una hora especial de iniciación de labores.

Facultad de Derecho y Ciencias Sociales - Universidad de Valparaíso - Chile 
Asimismo, tratándose de funcionarios que sigan cursos o estudios regulares de carácter universitario o de otros niveles educacionales, podrá fijárseles un horario especial de trabajo, siempre que se dé cumplimiento a las siguientes condiciones:

$[\ldots]$

El sistema de jornada continua en los Servicios Públicos no alterará el derecho de los empleados para desempeñar funciones que las leyes establecen como compatibles. Los Jefes de los respectivos Servicios regularán los horarios de los empleados que se encuentren en dicha situación.

Todos los Servicios de la Administración Civil del Estado destinarán por lo menos, 2 horas diarias para la atención del Público en las Oficinas que cada uno de ellos determine. Dicha jornada será uniforme en cada uno de los grupos de Servicios a que alude en el párrafo primero de esta letra y se fijará por el Presidente de la República; en casos calificados, podrá ser extendida por los respectivos Jefes Superiores de Servicio.

Tratándose de los Servicios que inicien sus labores entre las 10,00 y 11,00 , la atención del público deberá extenderse, necesariamente, hasta media hora antes del término de su jornada de trabajo.

[...]".

Como puede verse, los servicios públicos, en general, iniciarán sus labores entre las 8.30 y 9.00 horas, añadiendo su inciso séptimo que destinarán, por lo menos, dos horas diarias para la atención del público en las oficinas que cada uno de ellos determine.

La Contraloría General de la República ha precisado que la fijación de aquellas dos horas diarias mínimas corresponderá a los jefes superiores de los servicios, lo cual se materializará en una respectiva resolución interna. Así lo ha reconocido sostenidamente la Contraloría General de la República:

“...en lo que atañe a la fijación del horario de atención de público, es dable anotar que atendido que el referido Estatuto Administrativo no contempla normas que precisen la hora de inicio y

Revista de Ciencias Sociales - Número 69 (2016) - Universidad de Valparáíso - ISSN 0716-7725-Valparaíso, Chile 
término para tal efecto, la determinación del mismo corresponde al ejercicio de las facultades que el referido artículo 31 de la ley $\mathrm{N}^{\circ} 18.575$, reconoce a los jefes superiores de los servicios para dirigir, organizar y administrar el correspondiente organismo y velar por el cumplimiento de sus objetivos, por lo que esta materia es de plena facultad de la superioridad respectiva, quien debe ponderar su fijación, razón por la cual no compete a este Ente de Control dar instrucciones al respecto" (Dictamen $\mathrm{N}^{\circ} 33.628$, de 2016).

De esta forma, entonces, si se aceptase el criterio jurisprudencial que hace coincidir el término de los plazos administrativos con el del horario de atención al público, se estaría permitiendo que resoluciones administrativas internas sean las que establezcan, discrecionalmente, un elemento estructural de aquellos plazos. Esto no sería problemático si no existieran disposiciones legales expresas que regulan la materia, por lo cual, atendido el principio de juridicidad establecido en la Constitución y la LOCBGAE, debe rechazarse esa posibilidad.

\section{Las regulaciones legales de la jornada laboral de los funcionarios públicos no hacen excepción a las disposiciones del Código Civil}

El artículo 65 del Estatuto Administrativo dispone que la jornada ordinaria de trabajo de los funcionarios será de cuarenta y cuatro horas semanales distribuidas de lunes a viernes, no pudiendo exceder de nueve horas diarias. Lo anterior, por cierto, sin perjuicio de la ejecución de trabajos extraordinarios cuando hayan de cumplirse tareas impostergables, según lo dispuesto en el artículo 66 del mismo cuerpo lega ${ }^{17}$.

17. Estas normas disponen: "Artículo 65. La jornada ordinaria de trabajo de los funcionarios será de cuarenta y cuatro horas semanales distribuidas de lunes a viernes, no pudiendo exceder de nueve horas diarias.

La autoridad facultada para hacer el nombramiento podrá proveer cargos de la planta a jornada parcial de trabajo, cuando ello sea necesario por razones de buen servicio. En estos casos los funcionarios tendrán una remuneración proporcional al tiempo trabajado y de manera alguna podrán desempeñar trabajos extraordinarios remunerados.

Facultad de Derecho y Ciencias Sociales - Universidad de Valparaíso - Chile 
Dichas reglas no hacen ninguna referencia al término de los plazos administrativos, es decir, no contienen disposición alguna que se constituya en una norma especial que haga excepción a lo establecido, en términos generales y supletorios, en los artículos 48, 49 y 50 del Código Civil.

\section{Jurisprudencia de la Contraloría General de la República}

Si bien la Contraloría General de la República sostiene históricamente una interpretación radicalmente distinta, como se ha expuesto, tampoco ha desconocido del todo que es el Código Civil quien establece las normas referentes al término de los plazos administrativos.

En efecto, en un dictamen en el cual reitera su histórico criterio, planteó lo siguiente:

"Sin perjuicio de lo anterior, esa Dirección, puede arbitrar medidas seguras, confiables y de fácil acceso, a fin de percibir las solicitudes a que se refiere la presentación, hasta las 24 horas del día que vence el plazo, de conformidad a las normas contenidas en los artículos 48 y 49 del Código Civil" (Dictamen No 49.126, de 2008).

Dicho pronunciamiento constituye el germen del preclaro dictamen $\mathrm{N}^{\circ}$ 84.495, de 2016. Ambos, como se expondrán, permiten plantear una salida práctica para una interpretación jurídicamente correcta del problema del término de los plazos administrativos.

Los funcionarios deberán desempeñar su cargo en forma permanente durante la jornada ordinaria de trabajo".

"Artículo 66. El jefe superior de la institución, el Secretario Regional Ministerial o el Director Regional de servicios nacionales desconcentrados, según corresponda, podrá ordenar trabajos extraordinarios a continuación de la jornada ordinaria, de noche o en días sábado, domingo y festivos, cuando hayan de cumplirse tareas impostergables.

Los trabajos extraordinarios se compensarán con descanso complementario.

Si ello no fuere posible por razones de buen servicio, aquéllos serán compensados con un recargo en las remuneraciones".

Revista de Ciencias Sociales - Número 69 (2016) - Universidad de Valparáíso - ISSN 0716-7725-Valparaíso, Chile 
Finalmente, a este respecto, cabe resaltar que la propia jurisprudencia administrativa pareciera no ser tan tajante en esta materia, y ha reconocido la aplicación de las reglas del Código Civil.

\section{Jurisprudencia de la Corte Suprema}

Por último, resta señalar que la Corte Suprema sí ha seguido la interpretación correcta en esta materia, sosteniendo que cada vez que no se respeta la integridad de la extensión de un plazo legal, se da "un trato discriminatorio, que no puede ser aceptado". Asimismo, al cuestionarse cómo computar el término de un plazo administrativo, ha señalado que ello se resuelve aplicando las normas contenidas en el Código Civil.

No respetar un plazo administrativo en toda su extensión constituye una infracción a la igualdad ante la ley

La Corte Suprema ha tenido la ocasión de pronunciarse respecto a la ilegalidad que se comete cuando no se computa un plazo en toda su extensión, señalando de forma sostenida lo siguiente:

“...la actuación de la recurrida constituye un acto ilegal pues por ella se negó a tramitar un recurso presentado dentro de plazo legal, afectando la garantía de igualdad ante la ley contemplada en el artículo $19 \mathrm{~N}^{\circ} 2$ de la Constitución Política de la República, porque al desconocer la autoridad recurrida el término en toda su extensión ha dado un trato discriminatorio, que no puede ser aceptado" ${ }^{18}$ (SCS Rol No 18.432-2016, de fecha 19/05/2016. En este mismo sentido: SCS Rol No 13.686-2015, de fecha 19/11/ 2015; SCS Rol No 23996-2014, de fecha 06/11/2014; SCS Rol $N^{o} 8384-2014$, de fecha 08/07/2014; SCS Rol No 8.916-2011, de fecha 02/11/2011; SCS Rol No 3.545-2011, de fecha 21/06/2011; SCA Concepción Rol No 3.998-2016, de fecha 15/04/2016. Confirmada en la SCS Rol No 25.763-2016, de fecha 14/06/2016).

18. El destacado es mío.

Facultad de Derecho y Ciencias Sociales - Universidad de Valparaíso - Chile 
Si bien estos casos dicen relación respecto a irregularidades producto del mal cómputo de días inhábiles, en sede de recurso de protección, establecen un criterio del todo pertinente en lo referente a su término.

\section{Aplicación del Código Civil para determinar el término de plazos administrativos}

En materia tributaria se ha discutido el término legal de plazos administrativos y, contrariamente a lo sostenido por la Contraloría General de la República, la Corte Suprema ha resuelto aplicar, dado el carácter general y supletorio del Código Civil, los artículos 48, 49 y 50 tantas veces citado. Atendida la claridad de estos pronunciamientos, transcribiré el principal razonamiento en este punto:

"OCTAVO: Que, entonces, a la luz de las disposiciones citadas precedentemente aparece que el Servicio de Impuestos Internos debía liquidar los impuestos de autos y notificar dicha pretensión "dentro" del término que resulta de adicionar a los tres años que otorga el inciso $1^{\circ}$ del artículo 200 del Código Tributario, el plazo que otorga la citación - tres meses - y el de la prórroga. De acuerdo al mérito del proceso, entonces, nos encontramos, sucesivamente, ante un término de años, otro de meses y finalmente, uno de días.

NOVENO: Que de acuerdo al artículo 48 del Código Civil, todos los plazos antes citados — años, meses y días - que han sido prescritos por ley, han de ser completos y corren hasta la medianoche del último día de cada uno. A su turno, el artículo 49 mencionado prescribe que la ejecución de un acto que deba realizarse "dentro" de cierto plazo, como es el caso en estudio, es válida si se verifica antes de la medianoche en que termina el último día del mismo, de manera que no es posible admitir el razonamiento del recurso en orden a que el incremento otorgado en virtud de la citación comenzó a correr el mismo día de su decreto, ya que tal entendimiento se opone a lo que expresamente dispone la norma citada, al señalar: "Todos los plazos de días,

Revista de Ciencias Sociales - Número 69 (2016) - Universidad de Valparáíso - ISSN 0716-7725-Valparáiso, Chile 
meses o años de que se haga mención en las leyes o en los decretos del Presidente de la República, de los tribunales o juzgados, se entenderá que han de ser completos; y correrán hasta la medianoche del último día del plazo”, por lo que el término concedido durante el plazo de citación ha corrido desde el vencimiento del lapso completo que ella otorga y sus aumentos se agregan a los mismos. Sostener lo contrario, implicaría desconocer el tenor del artículo 48 mencionado, que ordena observarlos en su integridad.

Por ello, resulta forzoso concluir entonces que deben correr todos los términos otorgados por la ley en su integridad hasta la medianoche del último día de cada uno. Esto es, el de años, que venció el 30 de abril de 2009, y el de tres meses a contar de la expiración del primero, esto es, desde el 1 de mayo del mismo año que, así considerado, venció el 31 de julio siguiente y, para los efectos que interesa al recurso, el de un mes concedido, extendió la vigencia de la acción del Servicio de Impuestos Internos hasta fines de agosto de 2009.

DÉCIMO: Que, en consecuencia, efectuado el cálculo de la manera asentada precedentemente, queda en evidencia que la actuación del Servicio de Impuestos Internos al emitir las liquidaciones de autos y notificarlas el 26 de agosto de 2009 ha sido en tiempo, toda vez que el término con que contaba para liquidar, revisar y girar expiraba después de la referida fecha, en virtud de la prórroga otorgada por un mes, y que finalizó después de la fecha en que se practicó la notificación de las liquidaciones reclamadas". (SCS Rol No 22.442-2014, de fecha 07/01/2016. En el mismo sentido: SCS Rol No 23.544-14, de fecha 18/08/2015; SCS Rol No 677-2013, de fecha 07/10/2013; SCS Rol No 1412010, de fecha 18/12/2012).

Como puede verse, a un plazo administrativo que el Código Tributario impone a la Administración (en este caso, el Servicio de Impuestos Internos), a la hora de determinar su término, la Corte Suprema sostiene que deben aplicarse las disposiciones del Código Civil.

Facultad de Derecho y Ciencias Sociales - Universidad de Valparaíso - Chile 


\section{Una propuesta de solución: las posibilidades interpretativas de la LBPA según la Contraloría General de la República}

Pues bien, de todo lo desarrollado hasta acá, podrían plantearse objeciones relativas a los efectos indeseados que acarrearía respetar el término legal de los plazos administrativos, por cuanto exigiría contar con funcionarios ${ }^{19} \mathrm{o}$ algún sistema electrónico que permitan certificar la recepción de presentaciones de los particulares que acaezcan una vez finalizado el horario de atención al público, hasta la medianoche de cada día hábil.

Sin embargo, la propia Contraloría General de la República, como se expuso, en el dictamen $\mathrm{N}^{\circ}$ 49.126, de 2008, señaló que sería deseable que las reparticiones públicas arbitrasen medios para la recepción de presentaciones hasta el cumplimiento de la integridad del respectivo plazo.

Curiosamente, en dicha oportunidad, no reparó que la solución a aquello se encontraba vigente desde el año 2003, al publicarse la LBPA, que establece en sus artículos 5 y 19 la equivalencia jurídica entre el soporte material y el electrónico ${ }^{20}$. De manera que todo jefe superior de servicio, para dar cumplimiento a las exigencias del ordenamiento jurídico respecto a los plazos administrativos, podría instruir, por ejemplo, la difusión de una casilla electrónica para la recepción de presentaciones con posterioridad al término del horario de atención al público ${ }^{21}$.

19. Exigencia que, por lo demás, sería ilegal, de conformidad a la misma jurisprudencia del ente de control: “...el Estatuto Administrativo, al referirse a la forma como deben desarrollarse los trabajos propios del cargo, exige que estos se ejecuten de 'manera regular, continua o permanente', mediante el desempeño personal de las tareas encomendadas, durante la jornada ordinaria o extraordinaria, sin admitir la posibilidad de imponer a los funcionarios la obligación de permanecer ubicables y disponibles, fuera de esos horarios, a fin de atender eventuales labores, como sucede con los 'turnos de llamada' por los que se consulta” (Dictamen $N^{\circ} 15.848$, de 2016).

20. En efecto, la doctrina especializada señala que “...existe un marco jurídico que reconoce la posibilidad de realizar el procedimiento administrativo por medios electrónicos". MOYA, Rodrigo. "El procedimiento administrativo electrónico en Chile”. En: Revista Chilena de Derecho Informático, N 3, 2003. Pág. 81.

21. "El tema de los documentos electrónicos es una materia que ya se encuentra resuelta en la Ley 19.799 , la cual permitiría, en función del principio de

Revista de Ciencias Sociales - Número 69 (2016) - Universidad de Valparaíso - ISSN 0716-7725-Valparaíso, Chile 
Dicha posibilidad quedó abierta con el dictamen $\mathrm{N}^{\circ} 84.495$, de 2016. En dicha oportunidad se discutía si un reclamo de ilegalidad del artículo 156 de la ley $\mathrm{N}^{\circ} 18.883$ interpuesto por medios electrónicos fuera del horario de atención al público, pero antes de medianoche, había sido presentado oportunamente, resolviéndose por la afirmativa ${ }^{22}$. Nótese, en este punto, la inconsistencia que significa seguir afirmando que los plazos administrativos terminan una vez finalizada la atención

neutralidad tecnológica y homologación de soportes, presentar documentos electrónicos en cualquier tramitación, ante sede administrativa o judicial, sin necesidad de autorización expresa, en este caso, de la LBPA”. MOYA, Rodrigo. Op. Cit. Pág. 86.

22. “...cabe señalar que al tenor de lo preceptuado, en lo pertinente, en el artículo 48 , inciso primero, del Código Civil, todos los plazos de días a que se haga mención en las leyes se entenderá que han de ser completos y correrán, además, hasta la medianoche del último día del plazo. El inciso final de ese artículo prescribe que estas reglas se aplicarán, en general, a cualesquiera plazos o términos, salvo que en las mismas leyes que los establezcan se disponga expresamente otra cosa.

Enseguida, según lo establece el artículo 25 de la ley $\mathrm{N}^{\circ} 18.880$, se entiende que "son inhábiles los días sábados, los domingos y los festivos". Añade ese precepto que los plazos se computarán desde el día siguiente a aquel en que se notifique o publique el acto de que se trate.

También debe considerarse que los artículos $5^{\circ}$ y 19 de la citada ley $\mathrm{N}^{\circ} 19.880$ prevén, en lo que interesa, que por regla general el procedimiento administrativo y los actos a que da origen, pueden realizarse por escrito o a través de técnicas y medios electrónicos.

En la situación que interesa, atendido que el citado decreto alcaldicio $\mathrm{N}^{\circ} 4.316$ fue notificado el 15 de octubre de 2015, cabe concluir que en virtud de las normas antes reseñadas, el último día del plazo para interponer en su contra el reclamo antedicho era el 29 de octubre de ese año.

Pues bien, en esta oportunidad se han tenido a la vista antecedentes relativos a la fijación de la hora oficial en nuestro país y a la forma en que esta última se sincroniza con la de los servidores y computadores personales, según el procedimiento implementado por el Servicio Hidrográfico y Oceanográfico de la Armada, acorde con las atribuciones previstas en la ley $\mathrm{N}^{\circ} 16.771$.

Asimismo y en base a esa información, se consideró un informe técnico sobre la materia, emitido por el Centro de Informática de esta Contraloría General, en el cual se precisa que con arreglo a su plataforma de mensajería se ha identificado la recepción del mensaje electrónico que contiene la referida reclamación, en la casilla del correo institucional, a las 23 horas, con 26 minutos, del 29 de octubre de 2015.

En atención a estos nuevos antecedentes, se ha podido tener por acreditado que en la especie el señalado recurso de ilegalidad, contemplado en el artículo 156 de

Facultad de Derecho y Ciencias Sociales - Universidad de Valparaíso - Chile 
al público con la aceptación posterior de presentaciones; por cuanto de aceptarse lo primero, en especial, asumiendo su fundamento en disposiciones legales especiales, como antes se expuso, este segundo criterio significaría prorrogar ilegalmente plazos fenecidos; o, a la inversa, reconocer implícitamente que el plazo jamás feneció.

Sin embargo, el criterio de aceptar presentaciones electrónicas con posterioridad al término del horario de atención al público y hasta antes de medianoche es un correcto, y debiera servir de sustento jurídico para superar la postura anticuada que se critica en este trabajo.

Como luces que podrían anunciar un cambio jurisprudencial en dicho sentido, el correcto criterio sostenido en el dictamen $\mathrm{N}^{\circ} 84.495$, de 2016, será asentado en otro pronunciamiento, en los siguientes términos:

“...considerando que según los artículos $5^{\circ}$ y 19 de la ley $\mathrm{N}^{\circ} 19.880$, el procedimiento administrativo y los actos a que da origen pueden realizarse por escrito o a través de técnicas y medios electrónicos, no se advierte inconveniente en que, cuando se encuentre habilitada por el servicio de que se trate esta última vía para efectuar presentaciones, éstas puedan ingresarse fuera del horario de atención de público correspondiente en la plataforma que se contemple al efecto (aplica criterio contenido en el dictamen $\mathrm{N}^{\circ}$ 84.495, de 2016)" (Dictamen $\mathrm{N}^{\circ}$ 93.779, de 2016).

Por cierto, lo sostenido acá es una posibilidad interpretativa, entre otras, que podrían disponer los órganos de la Administración del Estado para dar cumplimiento al marco legal que regula el término de los plazos administrativos antes señalado. Debiera ser cada servicio el que, de conformidad a sus particularidades propias, determine el mejor mecanismo para dar cumplimiento a la ley.

la ley $\mathrm{N}^{\circ} 18.883$, ha sido interpuesto dentro del plazo legal, por lo que procede acoger la solicitud del recurrente en orden a reconsiderar el precitado oficio $\mathrm{N}^{\circ} 23.754$, de 2015" (Dictamen N 84.495, de 2016).

Revista de Ciencias Sociales - Número 69 (2016) - Universidad de Valparáíso - ISSN 0716-7725-Valparaíso, Chile 


\section{Conclusiones}

De lo previamente desarrollado, es posible arribar a un conjunto de conclusiones, a saber:

1. La Contraloría General de la República sostiene que los plazos administrativos tienen su término una vez finalizado el horario de atención al público de su último día. Dicho criterio jurisprudencial, que se remonta a la década de los 50', se ha mantenido hasta el día de hoy.

2. Lo anterior se fundamentaría en la existencia de normas especiales que regulan de manera diversa a como lo hace el Derecho Común, la forma en que se computan los plazos y su vencimiento, así como también el horario de funcionamiento de los servicios públicos. Dichas normas especiales serían aquellas referentes al (i) horario de atención al público de las reparticiones públicas; y (ii) la jornada de trabajo de los funcionarios públicos.

3. Sin embargo, para establecer correctamente el marco jurídico del término de los plazos administrativos resulta necesario incorporar al análisis dos modificaciones legales posteriores al surgimiento del criterio de la Contraloría: (i) la ley $\mathrm{N}^{\circ} 20.500$ que introduce el principio y derecho de participación ciudadana en la gestión pública; y (ii) la LBPA, en especial, lo referente a la equivalencia jurídica entre los soportes materiales y electrónicos de las actuaciones del procedimiento administrativo.

4. Así, considerando que la interpretación jurídica en esta materia ha de promover la participación ciudadana, y que las regulaciones relativas al cómputo de plazos administrativos contenidas en la LBPA no hacen excepción a normas generales y supletorias respecto al término de plazos contenidas en el Código Civil, es que debe concluirse que aquellos fenecen a media noche del último día del respectivo plazo.

5. De este modo, debe rechazarse la postura de la Contraloría General de la República por (i) entrabar ilegítimamente la participación ciudadana; (ii) porque ni la ley $\mathrm{N}^{\circ} 11.764$ ni el Estatuto Administrativo, en lo referente a la regulación del horario de atención al público y la jornada de trabajo de los servidores públicos, respectivamente, hacen

Facultad de Derecho y Ciencias Sociales - Universidad de Valparaíso - Chile 
excepción a las disposiciones de los artículos 48, 49 y 50 del Código Civil respecto al término de los plazos; (iii) dado que existen pronunciamientos de este mismo organismo que reconocen la aplicación de dicho código en este tópico; y, finalmente, (iv) porque la jurisprudencia de la Corte Suprema ha sido consistente en aplicar también aquellas disposiciones.

6. Finalmente, tampoco puede excusarse el respeto a la integridad del plazo administrativo en eventuales problemas prácticos que, probablemente, hacían muy razonable la postura de la Contraloría en décadas pasadas, toda vez que los avances tecnológicos y su reconocimiento legal permitirían recibir presentaciones una vez finalizado el horario de atención al público, sin necesidad de asignar estas labores a funcionarios o adquirir costosos sistemas electrónicos. Bastaría utilizar una casilla de correo electrónico. Curiosamente, también lo ha reconocido la jurisprudencia de la Contraloría General de la República.

\section{Bibliografía}

BERMÚDEZ, Jorge: Derecho Administrativo General. $3^{\text {a }}$ edición actualizada. Legalpublishing, Santiago, 2014.

CORDERO, Luis: Lecciones de Derecho Administrativo. Thomson Reuters, Santiago, 2015.

MORAGA, Claudio: Tratado de Derecho Administrativo. Tomo VII. La actividad formal de la Administración del Estado. AbeledoPerrot-

Legalpublishing, Santiago, 2010.

PINILLA, Álvaro: "Breves comentarios a las reglas vigentes para el cómputo de plazos o términos de origen legal". En: Revista de Derecho

Privado, $\mathrm{N}^{\circ}$ 24, 2013.

SCHMIDT-ASSMANN, Eberhard. "Pluralidad de estructuras y funciones de los procedimientos administrativos en el derecho alemán, europeo e internacional”. En: Barnés, Javier (Editor): La transformación del procedimiento administrativo. Global Law Press Editorial Derecho Global, Sevilla, 2008.

VERGARA, Alejandro: "Cómputo e interrupción de plazos en el procedimiento administrativo. Micrología del principio de certeza jurídica”. En: Soto, Eduardo (Coord.): Administración y Derecho. 
Homenaje a los 125 años de la Facultad de Derecho de la Pontificia Universidad Católica de Chile. Santiago, LegalPublishing, 2014.

Jurisprudencia judicial:

Sentencia de la Corte Suprema Rol No 3.545-2011, de fecha 21/06/2011. Sentencia de la Corte Suprema Rol No 8.916-2011, de fecha 02/11/2011. Sentencia de la Corte Suprema Rol No 141-2010, de fecha 18/12/2012. Sentencia de la Corte Suprema Rol No 677-2013, de fecha 07/10/2013. Sentencia de la Corte Suprema Rol No 8384-2014, de fecha 08/07/2014. Sentencia de la Corte Suprema Rol No 23996-2014, de fecha 06/11/2014. Sentencia de la Corte Suprema Rol No 23.544-14, de fecha 18/08/2015. Sentencia de la Corte Suprema Rol No 13.686-2015, de fecha 19/11/2015. Sentencia de la Corte Suprema Rol No 22.442-2014, de fecha 07/01/2016. Sentencia de la Corte de Apelaciones de Concepción Rol No 3.998 2016, de fecha 15/04/2016.

Sentencia de la Corte Suprema Rol No 25.763-2016, de fecha 14/06/2016. Sentencia Rol No 18.432-2016, de fecha 19/05/2016.

\section{Jurisprudencia del Tribunal Constitucional:}

Sentencia del Tribunal Constitucional Rol N 1868.

Sentencia del Tribunal Constitucional Rol N ${ }^{\circ} 1812$.

Sentencia del Tribunal Constitucional Rol N 1732.

\section{Dictámenes de la Contraloría General de la República:}

Dictamen $\mathrm{N}^{\circ} 43.317$, de 1958.

Dictamen $\mathrm{N}^{\circ} 1.610$, de 1976.

Dictamen $N^{\circ}$ 62.892, de 1978.

Dictamen No 8.678, de 1983.

Dictamen $\mathrm{N}^{\circ}$ 9.945, de 1990.

Dictamen $\mathrm{N}^{\circ}$ 28.647, de 1999.

Dictamen $\mathrm{N}^{\circ} 9.740$, de 2003.

Dictamen $\mathrm{N}^{\mathrm{o}} 49.126$, de 2008.

Dictamen $\mathrm{N}^{\circ}$ 19.353, de 2011.

Facultad de Derecho y Ciencias Sociales - Universidad de Valparaíso - Chile 
El término de los plazos administrativos: análisis crítico de la...

Dictamen $N^{\circ}$ 51.137, de 2011.

Dictamen $\mathrm{N}^{\circ}$ 19.980, de 2012.

Dictamen $\mathrm{N}^{\mathrm{o}} 35.714$, de 2014.

Dictamen $\mathrm{N}^{\circ} 15.848$, de 2016.

Dictamen $N^{\circ} 33.628$, de 2016.

Dictamen $\mathrm{N}^{\circ} 84.495$, de 2016.

Dictamen $N^{\circ}$ 93.779, de 2016.

Dictamen $\mathrm{N}^{\circ}$ 5.608, de 2017. 